\title{
Burden, risk factors and outcomes associated Check for
updates with gestational diabetes in a population-based cohort of pregnant women from North India
}

Stuti Bahl1,2, Neeta Dhabhai', Sunita Taneja' , Pratima Mittal ${ }^{3}$, Rupali Dewan³, Jasmine Kaur ${ }^{1}$, Ritu Chaudhary ${ }^{1}$, Nita Bhandari ${ }^{1}$ and Ranadip Chowdhury ${ }^{1 *}$

\begin{abstract}
Background: The burden of gestational diabetes mellitus (GDM) appears to be increasing in India and may be related to the double burden of malnutrition. The population-based incidence and risk factors of GDM, particularly in lower socio-economic populations, are not known. We conducted analyses on data from a population-based cohort of pregnant women in South Delhi, India, to determine the incidence of GDM, its risk factors and association with adverse pregnancy outcomes (stillbirth, preterm birth, large for gestational age babies) and need for caesarean section.
\end{abstract}

Methods: We analyzed data from the intervention group of the Women and Infants Integrated Interventions for Growth Study (WINGS), an individually randomized factorial design trial. An oral glucose tolerance test (OGTT) was performed at the time of confirmation of pregnancy, and for those who had a normal test ( $\leq 140 \mathrm{mg}$ ), it was repeated at 24-28 and at 34-36 weeks. Logistic regression was performed to ascertain risk factors associated with GDM. Risk ratios (RR) were calculated to find association between GDM and adverse pregnancy outcomes and need for caesarean section.

Results: $19.2 \%$ (95\% Cl: 17.6 to 20.9) pregnant women who had at least one OGTT were diagnosed to have GDM. Women who had prediabetes at the time of confirmation of pregnancy had a significantly higher risk of developing GDM (RR 2.08, 95\% Cl 1.45 to 2.97). Other risk factors independently associated with GDM were woman's age (adjusted OR (AOR) $1.10,95 \% \mathrm{Cl} 1.06$ to 1.15) and BMI (AOR 1.04, 95\% Cl 1.01 to 1.07). Higher maternal height was found to be protective factor for GDM (AOR 0.98, 95\% Cl 0.96 to 1.00). Women with GDM, received appropriate treatment did not have an increase in adverse outcomes and no increased need for caesarean section

Conclusions: A substantial proportion of pregnant women from a low to mid socio-economic population in Delhi had GDM, with older age, higher BMI and pre-diabetes as important risk factors. These findings highlight the need for interventions for prevention and provision of appropriate management of GDM in antenatal programmes.

Clinical trial registration: Clinical Trial Registry - India, \#CTRI/2017/06/008908 (http://ctri.nic.in/Clinicaltrials/pmain det2.php?trialid=19339\&EncHid=\&userName=society\%20for\%20applied\%20studies).

Keywords: Gestational diabetes mellitus, Stillbirth, Preterm, Caesarean section, Large for gestational age

*Correspondence: ranadip.chowdhury@sas.org.in

${ }^{1}$ Centre for Health Research and Development, Society for Applied

Studies, New Delhi, India

Full list of author information is available at the end of the article

\section{Background}

Gestational diabetes mellitus (GDM) is glucose intolerance that is first diagnosed during pregnancy most commonly at $24-28$ weeks gestation, typically reverting to 
normal after delivery [1]. The clinical effects of GDM can range from asymptomatic to those of severe hyperglycaemia [2]. GDM poses risks for both the mother and fetus. For women with GDM, elevated glucose levels during pregnancy increases their risk of having a caesarean delivery, and the tendency to develop type 2 diabetes later in life. It also increases the infants' risk of being born too large and developing obesity or diabetes in the future [3]. Women with GDM are also more likely to have recurrent GDM in subsequent pregnancies [4].

The estimated prevalence of GDM varies from $<1$ to $28 \%$ in different countries [5]. Data from high-income countries indicate that GDM complicates up to 12.4 to $25.5 \%$ of pregnancies [6]. In India, GDM is defined as 2-h Oral Glucose Tolerance Test [OGTT] $>140 \mathrm{mg} / \mathrm{dL}$ by the Diabetes in Pregnancy Study Group, India and in National Guidelines [7] . There is wide variability in reported prevalence estimates for gestational diabetes in India, varying from 7\% [8] to nearly $16 \%$ [9]. The burden of gestational diabetes appears to be increasing in India and may potentially be related to increasing prevalence of overweight or obesity [10]. There are limited data on population-based prevalence, risk factors and adverse outcomes of gestational diabetes, particularly in lower socio-economic populations.

We conducted analyses on data from a populationbased cohort of urban and peri-urban low-to-midsocioeconomic neighborhoods of South Delhi, India, to determine the incidence of gestational diabetes mellitus, its risk factors and association with adverse pregnancy outcomes (stillbirth, preterm birth, large for gestational age babies) and need for caesarean section.

\section{Methods}

\section{Study design, setting and participants}

We conducted this secondary analysis on data being collected as part of the Women and Infants Integrated Growth Study (WINGS). The study was conducted in urban and peri-urban low-to-mid-socioeconomic neighborhoods of South Delhi, India. A summary of the WINGS is provided below, details of methods have been previously published [11].

Briefly, eligible women aged between 18 and 30years were identified through a door-to-door survey. Women who provided written consent to participate in the study were enrolled (first randomization; to receive pre-and peri-conception interventions or routine care and followed up until their pregnancies were confirmed, or for 18 months after enrollment. Once pregnancy was confirmed by ultrasonography, written consent was obtained (second randomization; to receive enhanced antenatal, postnatal, and early childhood care or routine antenatal, postnatal, and early childhood care) from women for further participation in the study. For the current analysis, we included pregnant women from the intervention group.

Pregnant women in the intervention group received at least 8 antenatal care visits. Body mass index (BMI) and HbA1c assessments were done at the time of confirmation of pregnancy. A one step oral glucose tolerance test was performed at the time of confirmation of pregnancy, $75 \mathrm{mg}$ of anhydrous glucose was dissolved in $300 \mathrm{ml}$ of water and given orally to the participant (fasting or non fasting) and $2 \mathrm{~h}$ later a venous blood sample was taken, and blood sugar tested. In woman who had a blood sugar level $\leq 140 \mathrm{mg} / \mathrm{dl}$ defined as normal, OGTT was repeated at 24-28 weeks and at 34-36 weeks of gestation. Women who had $2 \mathrm{~h}$ blood sugar value of $>140 \mathrm{mg} / \mathrm{dl}$ were identified to have GDM using national criteria [7]. They were initially managed with dietary counseling. Thereafter, a fasting (FBS) and post prandial blood sugar (PPBS) was done after 2 weeks. Women with PPBS of $<120 \mathrm{mg} / \mathrm{dl}$ were continued on dietary management and tests were repeated monthly in second trimester and fortnightly in third trimester. In women with PPBS of $\geq 120 \mathrm{mg} / \mathrm{dl}$ medical management was initiated with Metformin or Insulin. Referral to the diabetic clinic of our collaborating tertiary care hospital was done for uncontrolled cases.

\section{Definitions}

GDM was defined as blood sugar $>140 \mathrm{mg} / \mathrm{dL}$ $(7.8 \mathrm{mmol} / \mathrm{L}) 2 \mathrm{~h}$ after ingesting $75 \mathrm{~g}$ glucose orally at any time during pregnancy using Government of India guidelines [7]. Prediabetes was defined if HbAlc values ranged between 5.7 to $6.4 \%$ [12]. Stillbirth was defined if a baby was born with no signs of life at or after 28 weeks of gestation [13]. Preterm birth was defined as babies born alive before 37 completed of weeks of pregnancy. Large for gestational age (LGA) was defined as infant's birth weight above the 90th percentile for gestational age using Intergrowth -21st Standards [14].

\section{Statistical analysis}

Sociodemographic characteristics were reported as mean (SD), or proportions as appropriate. We calculated incidence (95\% confidence interval: CI) of GDM occurring at any time during the pregnancy. We also calculated incidence of GDM based on gestational age; early abnormality those "Defined as OGTT > $140 \mathrm{mg} / \mathrm{dL}$ " based on the first trimester testing and (Late abnormality) those with normal or missing OGTT in the first trimesters but OGTT $>140 \mathrm{mg} / \mathrm{dL}$ based on the second/third-trimester testing. Univariable and multivariable logistic regressions were performed to ascertain risk factors associated with GDM. We also identified the potential risk factors for developing early and late GDM. The candidate variables 
were continuous (maternal age, height, years of schooling, early pregnancy (gestational age $\leq 20$ weeks) BMI, HbA1c) and categorical (religion (Hindu and others), type of family (extended or joint, and nuclear), family wealth quintiles). The family wealth index was calculated

Table 1 Sociodemographic characteristics of pregnant women

\begin{tabular}{|c|c|c|}
\hline Characteristics of pregnant women & $\begin{array}{l}\text { No GDM } \\
n=1814\end{array}$ & $\begin{array}{l}\text { GDM } \\
N=430\end{array}$ \\
\hline Age (years), mean (SD) & $23.5(3.1)$ & $24.7(3.0)$ \\
\hline Height (cm), mean (SD) & $152.4(5.6)$ & $151.9(5.8)$ \\
\hline Height $<150 \mathrm{~cm}$ & $614(33.8)$ & $162(37.7)$ \\
\hline \multicolumn{3}{|l|}{ Years of schooling } \\
\hline None (0) & $87(4.8)$ & $18(4.2)$ \\
\hline Primary $(1-5)$ & $157(8.6)$ & $41(9.5)$ \\
\hline Secondary (6-12) & $672(37.1)$ & $146(33.9)$ \\
\hline Higher than secondary (> 12) & $898(49.5)$ & $225(52.3)$ \\
\hline Working outside home & $90(5.0)$ & $18(4.2)$ \\
\hline $\begin{array}{l}\text { Early pregnancy BMI, mean (SD) } \\
\text { Underweight }\left(<18.5 \mathrm{~kg} / \mathrm{m}^{2}\right) \\
\text { Overweight or obesity }\left(\geq 25 \mathrm{~kg} / \mathrm{m}^{2}\right)\end{array}$ & $\begin{array}{l}21.9(3.9) \\
350(19.3) \\
374(20.6)\end{array}$ & $\begin{array}{l}23.1(4.2) \\
55(12.8) \\
137(31.9)\end{array}$ \\
\hline Hindu & $1492(82.3)$ & $359(83.5)$ \\
\hline \multicolumn{3}{|l|}{ Wealth quintiles } \\
\hline Poorest & $324(17.9)$ & $59(13.7)$ \\
\hline Very Poor & $308(17.0)$ & $68(15.8)$ \\
\hline Poor & $360(19.8)$ & $91(21.2)$ \\
\hline Less Poor & $380(20.9)$ & $94(21.9)$ \\
\hline Least Poor & $442(24.4)$ & $118(27.4)$ \\
\hline Nuclear familya & $609(33.6)$ & $145(33.7)$ \\
\hline
\end{tabular}

All values are numbers (percentages) unless stated otherwise

${ }^{a}$ Nuclear family consists of a married couple and their dependent children for each participant by performing a principal component analysis based on all 33 assets owned by the household as done in national surveys [15]. The total scores were used to divide the population into five equal wealth quintiles: the poorest, very poor, poor, less poor, and least poor. We calculated unadjusted and adjusted risk ratios (RR) and their 95\% CI for the association between GDM and adverse pregnancy outcomes (stillbirth, preterm birth, baby large for gestational age) and need for caesarean section. We also calculated unadjusted and adjusted RR between early or late GDM with adverse pregnancy outcomes including caesarean section. All statistical analyses were performed using STATA version 16 (StataCorp, College Station, TX, USA).

\section{Results}

In this study 2294 women were followed up from preconception period till delivery. Socioeconomic and clinical characteristics of enrolled women before pregnancy are shown in Table 1 . The study population was relatively young, with a mean (SD) age of 23.8 (3.1) years, about half of whom had higher than secondary school education, and with a monthly family income of about 20,000 INR (about 300 USD). Just over a third (, 34.9\%) had height less than $150 \mathrm{~cm}$. The mean (SD) BMI was 22.2 (4) $\mathrm{kg} / \mathrm{m} 2$ and there was dual burden of malnutrition, with $18 \%$ women underweight and $22.8 \%$ women overweight or obese (Table 1). We provided the flow diagram in supplementary Fig. 1.

Table 2 shows the proportion of enrolled women who developed GDM and those who had prediabetes before pregnancy. $19.2 \%$ (95\% CI: 17.6 to 20.9 ) pregnant women

Table 2 Proportion of women with gestational diabetes and with prediabetes before pregnancy

\begin{tabular}{|c|c|c|}
\hline Glycemic status & n (\%) & $95 \% \mathrm{Cl}$ \\
\hline Gestational diabetes identified anytime during pregnancy & $n=2244^{*}$ & \\
\hline Defined as OGTT > $140 \mathrm{mg} / \mathrm{dL} 1$ & $430(19.2)$ & 17.6 to 20.9 \\
\hline Defined as OGTT > $152.9 \mathrm{mg} / \mathrm{dL} 2$ & $233(10.4)$ & 9.2 to 11.7 \\
\hline Gestational diabetes identified during first trimester pregnancy (Early abnormality) & $n=1986^{*}$ & \\
\hline Defined as OGTT > $140 \mathrm{mg} / \mathrm{dL} 1$ & $112(5.6)$ & 4.7 to 6.7 \\
\hline Defined as OGTT > $152.9 \mathrm{mg} / \mathrm{dL} 2$ & $69(3.5)$ & 2.7 to 4.4 \\
\hline $\begin{array}{l}\text { Gestational diabetes identified during second or third trimester pregnancy (Late abnormal- } \\
\text { ity) }\end{array}$ & $n=2132^{*}$ & \\
\hline $\begin{array}{l}\text { Defined as OGTT }>140 \mathrm{mg} / \mathrm{dL} 1 \\
\text { Defined as OGTT }>152.9 \mathrm{mg} / \mathrm{dL} 2\end{array}$ & $\begin{array}{l}318(14.9) \\
n=2175^{*} \\
164(7.5)\end{array}$ & $\begin{array}{l}13.4 \text { to } 16.5 \\
6.5 \text { to } 8.7\end{array}$ \\
\hline $\mathrm{HbA} 1 \mathrm{c}$ status at the time of identification of pregnancy & $n=1854^{* *}$ & \\
\hline$<5.7$ & $1800(97.1)$ & 96.2 to 97.8 \\
\hline 5.7 to 6.4 & $50(2.7)$ & 2.0 to 3.5 \\
\hline$>6.4$ & $4(0.2)$ & 0.06 to 0.5 \\
\hline
\end{tabular}

${ }^{1}$ definition based on national guidelines; ${ }^{2}$ definition based on $\mathrm{WHO}$ guidelines

* 50 women did not have an OGTT during pregnancy: ** 440 missing values for HbA1c 
had GDM using national guidelines (2-h OGTT value of $>140 \mathrm{mg} / \mathrm{dL}$ ). $5.6 \%$ (95\% CI: 4.7 to 6.7 ) pregnant women were diagnosed in the first trimester and 14.9\% (95\% CI: 13.4 to 16.5$)$ were diagnosed in the second or third trimester. About $0.2 \%$ women had diabetes and $2.7 \%$ had prediabetes before pregnancy. Four cases identified with pre-existing diabetes were excluded from the analysis of predictors and outcomes of GDM.

Table 3 shows the association between baseline characteristics of women with gestational diabetes (2-h OGTT $>140 \mathrm{mg} / \mathrm{dL}$ anytime during pregnancy). Higher age (adjusted odds ratio (AOR) 1.10, 95\% CI 1.06 to 1.15 for each year), higher early-pregnancy BMI (AOR 1.04, 95\% CI 1.01 to 1.07 for each unit) and higher HbA1c (AOR $1.73,95 \% 1.23$ to 2.44 for each unit) were identified as risk factors for GDM. Woman's height was a protective factor (AOR $0.98,95 \%$ CI 0.96 to 1.00, $p=0.027$ for each $\mathrm{cm})$ for GDM.

Women who had prediabetes before pregnancy were at a higher risk for gestational diabetes (AOR 2.41, 95\% CI 1.31 to $4.44, p<=0.005$;)

Univariable and multivariable logistic regression was also performed to ascertain risk factors associated with GDM using WHO criteria (2-h OGTT > $153 \mathrm{mg} / \mathrm{dL}$ anytime during pregnancy) and baseline characteristics of women (Supplementary Table 1). The findings were similar to those obtained using national criteria (Supplementary Table 1). Univariable and multivariable logistic regression was also performed to ascertain risk factors associated with early and late GDM and baseline characteristics of women (Supplementary Table 2). We also assessed the risk factors for developing GDM any time during pregnancy categorizing early pregnancy BMI (normal BMI, underweight and overweight or obese) and HbA1c status $(<5.7 \%$ and $>=5.7 \%)$ at pregnancy confirmation (Supplementary Table 3). The findings were similar to Table 3.

Table 4 shows the association of GDM with adverse pregnancy outcomes in the context where management of GDM was supported by the research team. In this study, there was no significant association of GDM with stillbirth, preterm birth or LGA and caesarean section when we used OGTT $>140 \mathrm{mg} / \mathrm{dL}$ to define GDM. Similarly, we did not find an increased risk of caesarean section in pregnant women with GDM defined by WHO criteria (Supplementary Table 4). We also did not find any association between early or late GDM with adverse pregnancy outcomes and caesarean section (Supplementary Table 5).

\section{Discussion}

The main findings of this study are that $19.2 \%$ of a population-based cohort of pregnant women from urban and peri-urban low-to-mid-socioeconomic neighborhoods in South Delhi, India were diagnosed with GDM. In this population there is a dual burden of malnutrition, with $18 \%$ women being underweight and $22.8 \%$ women being overweight or obese. Older age, higher pre-pregnancy BMI and higherHbA1c level at confirmation of pregnancy were identified as risk factors for GDM and higher height was a protective factor. Women with GDM, received appropriate treatment in this study and did not have an increase in adverse outcomes such as stillbirths, preterm births and large for gestational age babies but were more likely to give birth by caesarean section than women without GDM.

Table 3 Potential risk factors for developing gestational diabetes (2-h OGTT > $140 \mathrm{mg} / \mathrm{dL}$ anytime during pregnancy) in enrolled women

\begin{tabular}{lll}
\hline Risk factors for GDM & Unadjusted OR (95\% Cl) & Adjusted OR (95\% Cl) \\
\hline Age (per 1 year) & $1.13(1.09$ to 1.17$) ; p<0.001$ & $1.10(1.06$ to 1.15$) ; p<0.001$ \\
Height (per 1 cm) & $0.99(0.97$ to 1.00$) ; p=0.137$ & $0.98(0.96$ to 1.00$) ; p=0.027$ \\
Schooling (per 1 year) & $1.01(0.98$ to 1.03$) ; p=0.658$ & $0.99(0.96$ to 1.02$) ; p=0.569$ \\
Working outside home & $0.84(0.50$ to 1.40$) ; p=0.500$ & $0.99(0.57$ to 1.72$) ; p=0.964$ \\
Nuclear family & $1.01(0.81$ to 1.26$) ; p=0.953$ & $0.97(0.74$ to 1.28$) ; p=0.837$ \\
Wealth quintile & & Reference \\
Poorest & Reference & $1.16(0.76$ to 1.80$) ; p=0.491$ \\
Very Poor & $1.21(0.83$ to 1.78$) ; p=0.323$ & $1.31(0.86$ to 2.01$) ; p=0.204$ \\
Poor & $1.39(0.97$ to 1.99$) ; p=0.074$ & $1.17(0.75$ to 1.81$) ; p=0.490$ \\
Less Poor & $1.36(0.95$ to 1.94$) ; p=0.093$ & $1.34(0.87$ to 2.07$) ; p=0.187$ \\
Least Poor & $1.47(1.04$ to 2.07$) ; p=0.029$ & $0.90(0.65$ to 1.24$) ; p=0.519$ \\
Non-Hindu religion & $0.92(0.69$ to 1.21$) ; p=0.543$ & $1.04(1.01$ to 1.07$) ; p=0.013$ \\
Pre-pregnancy BMl (kg/m2) (per 1 unit) & $1.07(1.05$ to 1.10$) ; p<0.001$ & $1.73(1.23$ to 2.44$) ; p=0.002$ \\
HbA1c (\%) at pregnancy confirmation (per 1 percentage) & $2.05(1.47$ to 2.87$) ; p<0.001$ &
\end{tabular}


Table 4 Association between gestational diabetes mellitus (2-h OGTT > $140 \mathrm{mg} / \mathrm{dL}$ ) and adverse pregnancy outcomes

\begin{tabular}{|c|c|c|c|c|}
\hline Outcome & $\begin{array}{l}\text { No GDM } \\
\text { n (\%) }\end{array}$ & $\begin{array}{l}\text { GDM } \\
\text { n (\%) }\end{array}$ & $\begin{array}{l}\text { Unadjusted } \\
\text { RR }(95 \% \mathrm{Cl})\end{array}$ & $\begin{array}{l}\text { Adjusted RR } \\
(95 \% \mathrm{Cl})\end{array}$ \\
\hline Stillbirth & $\begin{array}{l}N=1782 \\
24(1.3)\end{array}$ & $\begin{array}{l}N=430 \\
3(0.7)\end{array}$ & 0.52 (0.16 to 1.71$)$ & 0.55 (0.16 to 1.84$)$ \\
\hline Preterm birth & $\begin{array}{l}N=1782 \\
230(12.9)\end{array}$ & $\begin{array}{l}N=430 \\
48(11.2)\end{array}$ & 0.86 (0.65 to 1.16$)$ & 0.77 (0.53 to 1.11$)$ \\
\hline Large for gestational age & $\begin{array}{l}N=1627 \\
21(1.3)\end{array}$ & $\begin{array}{l}N=406 \\
8(2.0)\end{array}$ & 1.53 (0.68 to 3.42$)$ & 1.11 (0.49 to 2.52 ) \\
\hline Caesarean section & $\begin{array}{l}N=1757 \\
519(29.5)\end{array}$ & $\begin{array}{l}N=427 \\
148\end{array}$ & 1.17 (1.01 to 1.36$)$ & 1.05 (0.87 to 1.26$)$ \\
\hline
\end{tabular}

a adjusted for maternal age, height, years of schooling, early pregnancy (gestational age $\leq 20$ weeks) BMI, HbA1C, religion, type of family, family wealth quintiles

Previous studies have shown a wide variation in the prevalence of GDM from different states in India [8, 16-18]. The geographical differences in prevalence of gestational diabetes have been attributed to differences in mean age, BMI and socioeconomic status of pregnant women from different regions of the country [19]. Using the same cut-off (WHO, 2-h blood sugar $>153 \mathrm{mg} / \mathrm{dL}$ ) for defining GDM, the prevalence of GDM in our study was almost similar (10.4\%) as that in developed countries (12.5 to $25.5 \%$ ) [6]. Our findings related to adverse pregnancy outcomes are similar to previous studies which have shown that treatment of GDM reduces the incidence of fetal macrosomia, mortality, birth trauma, and caesarean section deliveries $[20,21]$.

A major strength of our study is that it is a population-based assessment of GDM in women belonging to the low to mid socioeconomic strata, which is more representative of the average Indian population. In addition to providing the burden and risk factors of GDM, we also studied the association of this condition, when it was identified early and managed appropriately, with adverse pregnancy outcomes. The study also examined the risk associated with pre-diabetes at the time of pregnancy identification with GDM, and with adverse pregnancy outcomes. We used a single 2-h OGTT value at any time during pregnancy to detect GDM, which is feasible in a setting like India, where the pregnant women may not return after the first visit due to financial constraints, lack of accessibility of a health care centre and other reasons. Some limitations merit consideration. OGTT was carried on fasted and non-fasted patients which could result in false-positive GDM cases [22]. The high incidence of GDM may not be generalizable to other low- and middle-income countries as different criteria have been used to define GDM in countries [5].

This study has important programmatic implications. First, the high burden of GDM even in low socio-economic populations highlights the need to focus on its prevention, early detection and management in antenatal care programmes. Secondly, preventive interventions should target key risk factors including lowering the prevalence of obesity and overweight in women of reproductive age and detecting and managing pre-diabetes. Finally, early detection and appropriate management is not likely to increase the adverse pregnancy outcomes associated with GDM.

\section{Conclusions}

A substantial proportion of pregnant women from urban and peri-urban low-to-mid-socioeconomic neighborhoods in Delhi had GDM, with older age, higher BMI and pre-diabetes as important risk factors and taller woman as a protective factor. These findings highlight the need for interventions for prevention and provision of appropriate management of GDM in antenatal programmes.

\section{Abbreviations}

95\% Cl: 95\% Confidence Interval; AOR: Adjusted Odds Ratio; BMI: Body mass index; GDM: Gestational diabetes mellitus; LGA: Large for gestational age; OGTT: Oral glucose tolerance test; WINGS: Women and Infants Integrated Interventions for Growth Study; WHO: World Health Organisation.

\section{Supplementary Information}

The online version contains supplementary material available at https://doi. org/10.1186/s12884-022-04389-5.

Additional file 1

\section{Acknowledgements}

The Society for Applied Studies acknowledges the core support provided by the Department of Maternal, Newborn, Child and Adolescent Health, World Health Organization, Geneva (WHO Collaborating Centre IND-158). We acknowledge the contribution and support of the mothers and families and others in the community.

Authors' contributions

$R C, S B, N D, S T, R B$ were involved in conceptualizing research questions, preparation of data file, statistical analysis, data interpretation, manuscript writing, editing and finalization. PM, RD, JK, RC, NB were involved in revising 
the manuscript critically for important intellectual content. All authors have read and approved the final manuscript.

\section{Funding}

The main trial (WINGS) is funded by the Biotechnology Industry Research Assistance Council (BIRAC), Department of Biotechnology, Government of India under the Grand Challenges India - All Children Thriving Initiative (GClACT Ref No: BIRAC/GCI/0085/03/14-ACT) and the Bill \& Melinda Gates Foundation, USA (Grant ID \#OPP1 191052). The funding agencies did not play any role in study design and are neither involved in nor have any influence over the collection, analyses or interpretation of data.

\section{Availability of data and materials}

The Society for Applied Studies, India is a collaborator in the Healthy Birth, Growth, and Development Knowledge Integration (HBGDKi) initiative launched by the Bill \& Melinda Gates Foundation. The data generated from the study will be shared with the HBGDKi repository (https://github.com/ HBGDki). However, individual requests can be considered on a case-by-case basis. The request for data along with the detailed proposal describing the intended scientific question(s) to be addressed, should be submitted to Dr. Sunita Taneja (sunita.taneja@sas.org.in).

\section{Declarations}

\section{Ethics approval and consent to participate}

The Ethics Review Committees of the Society for Applied Studies, Vardhman Mahavir Medical College and Safdarjung Hospital, and the World Health Organization, Geneva have approved the study to be conducted with the relevant guidelines and regulations (e.g. Declaration of Helsinki) Written informed consent was obtained from the study participants.

\section{Consent for publication}

Not Applicable.

\section{Competing interests}

The authors declare that they have no competing interests.

\section{Author details}

${ }^{1}$ Centre for Health Research and Development, Society for Applied Studies, New Delhi, India. ${ }^{2}$ Amrita Institute of Medical Sciences, Kochi, India. ${ }^{3}$ Vardhman Mahavir Medical College and Safdarjung Hospital, New Delhi, India.

Received: 24 June 2021 Accepted: 10 January 2022

Published online: 14 January 2022

\section{References}

1. Metzger BE, Coustan DR. Summary and recommendations of the Fourth International Workshop-Conference on Gestational Diabetes Mellitus. The Organizing Committee. Diabetes care. 1998;21(Suppl 2):B161-7.

2. Kjos SL, Buchanan TA. Gestational diabetes mellitus. N Engl J Med. 1999;341(23):1749-56.

3. Zhu Y, Zhang C. Prevalence of gestational diabetes and risk of progression to type 2 diabetes: a global perspective. Curr Diab Rep. 2016;16(1):7.

4. MacNeill S, Dodds L, Hamilton DC, Armson BA, VandenHof M. Rates and risk factors for recurrence of gestational diabetes. Diabetes Care. 2001;24(4):659-62.

5. Jiwani A, Marseille E, Lohse N, Damm P, Hod M, Kahn JG. Gestational diabetes mellitus: results from a survey of country prevalence and practices. J Maternal-Fetal Neonatal Med. 2012;25(6):600-10.

6. Sacks DA, Hadden DR, Maresh M, Deerochanawong C, Dyer AR, Metzger $\mathrm{BE}$, et al. Frequency of gestational diabetes mellitus at collaborating centers based on IADPSG consensus panel-recommended criteria: the hyperglycemia and adverse pregnancy outcome (HAPO) study. Diabetes Care. 2012;35(3):526-8.

7. India. MHDMoHaFWGo: Diagnosis \& Management of Gestational Diabetes Mellitus. Technical and Operational Guidelines. In.; 2018

8. Swami SR, Mehetre R, Shivane V, Bandgar TR, Menon PS, Shah NS. Prevalence of carbohydrate intolerance of varying degrees in pregnant females in western India (Maharashtra)--a hospital-based study. J Indian Med Assoc. 2008;106(11):712-4 735.

9. Seshiah V, Balaji V, Balaji MS, Sanjeevi CB, Green A. Gestational diabetes mellitus in India. J Assoc Physicians India. 2004;52:707-11.

10. Chu SY, Callaghan WM, Kim SY, Schmid CH, Lau J, England LJ, Dietz PM: Maternal Obesity and Risk of Gestational Diabetes Mellitus 2007, 30(8):2070-2076.

11. Taneja S, Chowdhury R, Dhabhai N, Mazumder S, Upadhyay RP, Sharma S, Dewan R, Mittal P, Chellani H, Bahl R et al: Impact of an integrated nutrition, health, water sanitation and hygiene, psychosocial care and support intervention package delivered during the pre- and peri-conception period and/or during pregnancy and early childhood on linear growth of infants in the first two years of life, birth outcomes and nutritional status of mothers: study protocol of a factorial, individually randomized controlled trial in India. Trials 2020, 21(1):127.

12. Rudan I, O'Brien KL, Nair H, Liu L, Theodoratou E, Qazi S, et al. Epidemiology and etiology of childhood pneumonia in 2010: estimates of incidence, severe morbidity, mortality, underlying risk factors and causative pathogens for 192 countries. J Glob Health. 2013;3(1):010401.

13. Taneja S, Strand TA, Kumar T, Mahesh M, Mohan S, Manger MS, et al. Folic acid and vitamin B-12 supplementation and common infections in 6-30-mo-old children in India: a randomized placebo-controlled trial. Am J Clin Nutr. 2013;98(3):731-7.

14. Villar J, Cheikh Ismail L, Victora CG, Ohuma EO, Bertino E, Altman DG, Lambert A, Papageorghiou AT, Carvalho M, Jaffer YA et al: International standards for newborn weight, length, and head circumference by gestational age and sex: the Newborn Cross-Sectional Study of the INTERGROWTH21st Project. Lancet (London, England) 2014, 384(9946):857-868.

15. Balram Paswan SKS, Hemkhothang Lhungdim, Chander Shekhar, Fred Arnold, Sunita Kishor, Abhishek Singh, Dhananjay W. Bansod, Manoj Alagarajan, Laxmi Kant Dwivedi, Sarang Pedgaonkar,Manas R. Pradhan: International Institute for Population Sciences (IIPS) and Macro International. National Family Health Survey (NFHS-4). In.; DECEMBER 2017.

16. Bhatt AA, Dhore PB, Purandare VB, Sayyad MG, Mandal MK, Unnikrishnan AG. Gestational diabetes mellitus in rural population of Western India - results of a community survey. Indian J Endocrinology Metab. 2015;19(4):507-10.

17. Gopalakrishnan V, Singh R, Pradeep Y, Kapoor D, Rani AK, Pradhan S, et al. Evaluation of the prevalence of gestational diabetes mellitus in north Indians using the International Association of Diabetes and Pregnancy Study groups (IADPSG) criteria. J Postgrad Med. 2015;61(3):155-8.

18. Arora GP, Thaman RG, Prasad RB, Almgren P, Brøns C, Groop LC, et al. Prevalence and risk factors of gestational diabetes in Punjab, North India: results from a population screening program. Eur J Endocrinol. 2015;173(2):257-67.

19. Mithal A, Bansal B, Kalra S. Gestational diabetes in India: science and society. Indian J Endocrinology Metab. 2015;19(6):701-4.

20. Crowther CA, Hiller JE, Moss JR, McPhee AJ, Jeffries WS, Robinson JS. Effect of treatment of gestational diabetes mellitus on pregnancy outcomes. N Engl J Med. 2005;352(24):2477-86.

21. Landon MB, Spong CY, Thom E, Carpenter MW, Ramin SM, Casey B, et al. A multicenter, randomized trial of treatment for mild gestational diabetes. N Engl J Med. 2009;361(14):1339-48.

22. Masood SN, Lakho N, Saeed S, Masood Y. Non-fasting OGTT versus fasting OGTT for screening of Hyperglycaemia in pregnancy (HIP). Pakistan J Med Sci. 2021;37(4):1008-13.

\section{Publisher's Note}

Springer Nature remains neutral with regard to jurisdictional claims in published maps and institutional affiliations. 